\title{
Transfer RNA modifications that alter +1 frameshifting in general fail to affect -1 frameshifting
}

\author{
JAUNIUS URBONAVIČIUS, ${ }^{1,5}$ GUILLAUME STAHL, ${ }^{2,3}$ JÉRÔME M.B. DURAND, ${ }^{1}$ SAMIA N. BEN SALEM, ${ }^{2}$ \\ QIANG QIAN, ${ }^{\mathbf{P}}$ PHILIP J. FARABAUGH, ${ }^{\mathbf{1 , 2}}$ and GLENN R. BJÖRK ${ }^{\mathbf{1}}$ \\ ${ }^{1}$ Department of Molecular Biology, Umeå University, SE-90 187 Umeå, Sweden \\ ${ }^{2}$ Department of Biological Sciences and Program in Molecular and Cell Biology, University of Maryland Baltimore County, \\ Baltimore, Maryland 21250, USA
}

\begin{abstract}
Using mutants (tgt, mnmA(asuE, trmU), mnmE(trmE), miaA, miaB, miaE, truA(hisT), truB) of either Escherichia coli or Salmonella enterica serovar Typhimurium and the trm5 mutant of Saccharomyces cerevisiae, we have analyzed the influence by the modified nucleosides Q34, $\mathrm{mnm}^{5} \mathrm{~s}^{2} \mathrm{U} 34, \mathrm{~ms}^{2}{ }^{2}{ }^{6} \mathrm{~A} 37, \Psi 39, \Psi 55, \mathrm{~m}^{1} \mathrm{G} 37$, and yW37 on -1 frameshifts errors at various heptameric sequences, at which at least one codon is decoded by tRNAs having these modified nucleosides. The frequency of -1 frameshifting was the same in congenic strains only differing in the allelic state of the various tRNA modification genes. In fact, in one case (deficiency of $\mathrm{mnm}^{5} \mathrm{~s}^{2} \mathrm{U} 34$ ), we observed a reduced ability of the undermodified tRNA to make a -1 frameshift error. These results are in sharp contrast to earlier observations that tRNA modification prevents +1 frameshifting suggesting that the mechanisms by which -1 and +1 frameshift errors occur are different. Possible mechanisms explaining these results are discussed.
\end{abstract}

Keywords: Translation, tRNA modification, nucleoside, frameshifting

\section{INTRODUCTION}

Many retroviruses express Gag-Pol or Gag-Pro-Pol proteins by coupling their translation from overlapping reading frames with -1 ribosomal frameshifts (Farabaugh 2000). The frameshift event occurs on a distinctive heptameric sequence of the general form X-XXY-YYZ, where $\mathrm{X}$ is any nucleotide, $\mathrm{Y}$ is $\mathrm{A}$ or $\mathrm{U}$, and $\mathrm{Z}$ can be any nucleotide (Dinman et al. 1991; Jacks et al. 1988). From studies on the Rous sarcoma virus gag-pol frameshifting region, a pretranslocation "simultaneous slippage" model was proposed to explain the mechanism of frameshifting at such sequences (Jacks et al. 1988). According to this model, the frameshifting occurs before translocation and simultaneously by the two tRNAs present in the P- and A-sites. Later, an alterna-

Reprint requests to: Glenn R. Björk, Department of Molecular Biology, Umeå University, SE-90 187 Umeå, Sweden; e-mail: Glenn.Bjork@molbiol. umu.se.

Present addresses: ${ }^{3}$ Centre National de la Recherche Scientifique (CNRS), LMGM-IBCG, 118 route de Narbonne, 31062 Toulouse, France; ${ }^{4}$ TeleCommunication System Inc., Annapolis, MD 21401, USA; ${ }^{5}$ Laboratoire d'Enzymologie et Biochimie Structurals (LEBS), Centre National de la Recherche Scientifique (CNRS), Bldg. 34-1, Av de la Terasse, F-91 198 Gif-sur-Yvette, France

Article and publication are at http://www.rnajournal.org/cgi/doi/ 10.1261/rna.5210803. tive hypothesis was presented that suggested that the frameshifting event occurs after translocation when the codons in the heptameric sequence occupy the E- and P-sites (Horsfield et al. 1995). Another type of -1 frameshifting at sites not containing this kind of heptameric sequences occurs when the ribosome is stalled at a "hungry codon" induced by, for example, aminoacyl-tRNA limitation (Weiss and Gallant 1983) or at nonsense codons (Weiss et al. 1987, 1990). The peptidyl-tRNA was proposed first to slip in the 5 ' direction allowing the amino acid-tRNA in the A-site to decode the codon now at the newly formed frame by cognate interaction (Weiss et al. 1990; Yelverton et al. 1994; Barak et al. 1996).

The most energy-consuming process in the cell is translation of the genetic message transmitted via mRNA. In this process, it is pivotal for the ribosome to maintain the reading frame. Because the message lacks punctuations that would identify the reading frame, the ribosome cannot correct a reading frame error. Therefore, the translation machinery has evolved to reduce such errors to at least a magnitude lower in frequency than missense errors (Kurland et al. 1996). Transfer RNA is the molecule that decodes the message, and therefore it may be an important contributor to the reading frame maintenance. Changes in the tRNA structure, such as those induced by lack of a modified nucleoside, may therefore affect the reading frame mainte- 
nance. Modified nucleosides are derivatives of the four major nucleosides U, C, A, and G. At present, 81 different modified nucleosides have been characterized (Rozenski et al. 1999). Although they are present at different positions of the tRNA, most of them are present in the anticodon region and especially at positions 34 (wobble position) and 37 ( $3^{\prime}$ of and adjacent to the anticodon). Recently, we have demonstrated that the presence of several different modifications in the tRNA prevents +1 frameshifting (Urbonavičius et al. 2001). In that work, we also described a model explaining how frameshifting is promoted by hypomodified tRNA (see Fig. 1). This model has features in common with three of the above described models (Weiss et al. 1990; Horsfield et al. 1995; Barak et al. 1996) and with a recently described model to explain how +1 frameshifts occur (Stahl et al. 2002). We suggested that the same mechanism might

\section{A-site effect by modification deficient tRNA \\ P-site effect by modification deficient tRNA}

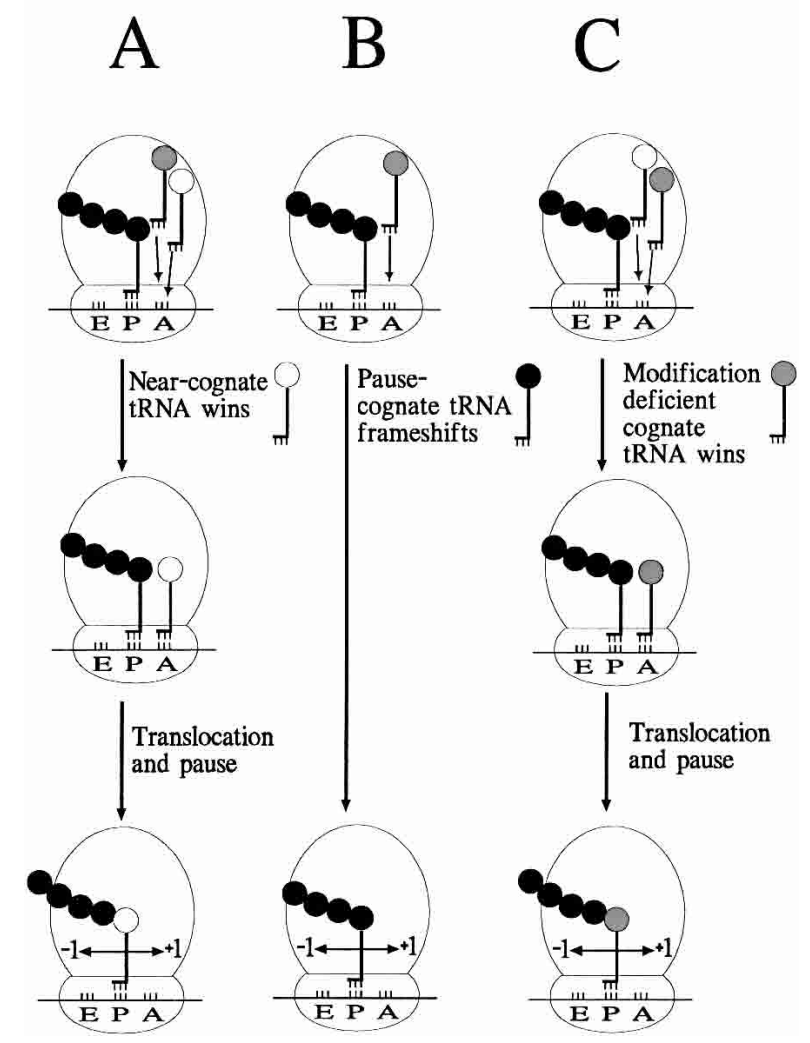

FIGURE 1. A dual-error model for frameshifting (Urbonavičius et al. 2001). (A) Hypomodified cognate tRNA is defective in the amino acid-tRNA selection step, thereby allowing a wild-type near-cognate tRNA to be accepted instead at the A-site. After a normal 3-nt translocation, the near-cognate tRNA slips into either -1 or +1 frame depending on the sequence of the mRNA. (B) The hypomodified tRNA is very slow in entering the A-site, inducing a pause, thereby allowing the wild-type tRNA in the P-site to frameshift into either -1 or +1 frame. $(C)$ As in $A$, but the hypomodified cognate tRNA is accepted in the A-site and when residing in the P-site, the hypomodification induces slippage into the -1 or +1 frame. also apply for -1 frameshifting errors. In the present work, we tested this hypothesis for several tRNA modifications. Surprisingly, our results demonstrate that in contrast to the +1 frameshifting (Urbonavičius et al. 2001), most tRNA modifications tested have no or in one case a slight stimulatory effect on -1 frameshifting. We suggest that in sharp contrast to the pivotal role of tRNA modification in preventing +1 frameshift errors, tRNA modification has no major role in preventing -1 frameshifting and that intrinsic features of the ribosome prevent this kind of errors.

\section{RESULTS}

\section{The working model and the experimental systems used}

Modification of tRNA may affect the accuracy of translation either by altering the rate tRNAs bind to the ribosome or by modulating the interaction of the tRNA $\cdot m R N A$ complex with the ribosome. Recruitment of each successive cognate, in-frame tRNA must occur in competition with all other tRNAs, including those that may decode out of frame; altering the rate of recruitment of cognate tRNA could change this competition to allow more frequent errant decoding. Alternatively, modification may modulate the interaction with the ribosome to ensure continued cognate, in-frame decoding by successive tRNAs. Figure 1 shows our model predicting how tRNA modification might influence reading frame maintenance. In all cases discussed below, the frameshift event occurs by peptidyl-tRNA slippage, although the identity of the tRNA that slips differs in each case. In the first case (Fig. 1A), hypomodification of a cognate tRNA might reduce its affinity for the codon in the ribosomal A-site. Because of its decreased rate of binding to the A-site, a wild-type near-cognate tRNA might successfully outcompete it, and be accepted into the A-site. After a normal 3-nt translocation, this near-cognate peptidyl-tRNA might not be able to interact optimally with the ribosomal P-site. Such nonoptimal P-site interaction has been suggested to reduce the efficiency of in-frame decoding leading to +1 frameshift errors (Belcourt and Farabaugh 1990; Urbonavičius et al. 2001). These errors are thought to result from slippage of peptidyl-tRNA prior to A-site recruitment. In principle, slippage in either the +1 or -1 direction might be possible, resulting in +1 or -1 frameshift errors. (P-site effect of near-cognate tRNA). In the second case (Fig. 1B), slow A-site recruitment of an undermodified cognate tRNA might induce frameshifting by causing a translational pause that allows a cognate wild-type peptidyl-tRNA in the P-site to slip either +1 or -1 (A-site effect by undermodified tRNA). Alternatively, in the third case, the defect of the undermodified cognate tRNA may not be in the A-site selection step, but rather undermodification may disrupt its interaction with the P-site after translocation (Fig. 1C). Undermodification might make the anticodon-codon interac- 
tion less optimal, as with the interaction by a near-cognate tRNA, resulting in an increased frequency of frameshifting (P-site effect by undermodified tRNA). Of course, hypomodification may cause frameshifting by mediating both A-site and P-site effects. Thus, in contrast to the simultaneous slippage model (Jacks et al. 1988), this model does not require a simultaneous slippage of both A- and P-sitelocated tRNAs, and the frameshifting event occurs after translocation. Our model has features in common with the model presented by Horsfield et al. (1995) and by Gallant and coworkers (Weiss and Gallant 1986).

Recently, we have demonstrated that a common function of several modified nucleosides in tRNA is to prevent +1 frameshifting (Urbonavičius et al. 2001). In the present work, we have investigated the influence of various modified nucleosides on -1 frameshifting using several assay systems (Table 2 , see below). To monitor -1 frameshifting in the bacteria Escherichia coli and Salmonella enterica, the HIV gag-pol programmed frameshifting site ( $\mathrm{pHIV-1}$; UUUU-UUA), the mouse mammary tumor virus (MMTV) gag-pro programmed frameshifting site (A-AAA-AAC), and the nonprogrammed $\operatorname{argI}$ gene frameshifting site (G-UUUUAU) were used. In these sequences, the first triplet denotes the codon in P-site, and the last triplet denotes the codon in A-site before the shift into the -1 frame has occurred ac- cording to the simultaneous slippage model (Jacks et al. 1988). In all cases, the lac $Z$ gene is placed downstream from a short frameshifting window in such a way that the $\beta$-galactosidase activity is a direct measurement of the frequency by which the ribosome shifts to the -1 frame within this window (Table 1). Previously, both HIV and MMTV sequences were shown to stimulate frameshifting in E. coli (Weiss et al. 1989; Yelverton et al. 1994). Furthermore, in E. coli, a -1 frameshifting site in the argI gene was also demonstrated (Fu and Parker 1994). Therefore, these assay systems are suitable to test the influence of tRNA modifications on -1 frameshifting in bacteria. In the eukaryote Saccharomyces cerevisiae, the HIV gag-pol programmed frameshifting site (U-UUU-UUA) and the L-A virus frameshifting site (G-GGU-UUA) were tested. Both HIV and L-A sequences are prone to frameshift in S. cerevisiae (Stahl et al. 1995; Kurland et al. 1996). In this case, the activity of luciferase was the measurement of frequency by which the ribosome shifts frame.

According to our model (Fig. 1), lack of $\mathrm{ms}^{2}$ io $^{6} \mathrm{~A} 37$ of, for example, the $\mathrm{RNA}_{\mathrm{cmnm} 5 \mathrm{UmAA}}^{\mathrm{Leu}}$ may affect the A-site selection step of tRNAs at the HIV frameshifting sites (Table 2 ). This would stimulate a frameshifting event at the P-site, mediated by $\mathrm{RRNA}_{\mathrm{GAA}}^{\mathrm{Phe}}$ (A-site effect by the undermodified tRNA; Urbonavičius et al. 2001). Alternatively, the frame-

TABLE 1. Plasmids and strains used

\begin{tabular}{|c|c|c|}
\hline Plasmid & Sequence of the frameshifting window & Source/Reference \\
\hline pHIV-1 & AUG-AAA-AGC-UUA-GCU-AAU-UUU-UUA-GG-GGA-GAU-CUG-GCC-UUC-lacZ & Weiss et al. 1989 \\
\hline pMMTV1284 & AUG-AAA-AGC-UUA-GCU-GAA-AAU-UCA-AAA-AAC-UU-GUA-AAG-GGG-lacZ & Weiss et al. 1989 \\
\hline pCFP3 & AAUUC-AUG-UCC-GGG-UUU-UAU-CAC-AAG-CAU-UUC-AUC-AAA-UA(AGC-lacZ & Fu and Parker 1994 \\
\hline pAC1789 & lacZ-CAG-GCU=AAU-UUU-UUA-GG-GGA-GA---/uc & Stahl et al. 1995 \\
\hline pAC1790 & lacZ-CAG-GCU-AAU-UUU-UUA-AGG-GGA-GA---luc & Stahl et al. 1995 \\
\hline pAC-LA & lacZ-UGG-CAG-CAG-GGU-UUA-GGA-GUG-GUA---luc & Bidou et al. 2000 \\
\hline pAC-LAFF & 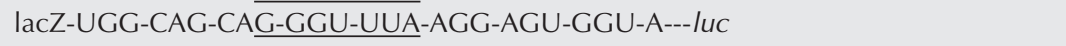 & This work \\
\hline Strain & Relevant genotype or phenotype & Source/Reference \\
\hline \multicolumn{3}{|c|}{ S. typhymurium } \\
\hline LT2 & wild type & J. Roth, Utah \\
\hline TT5866 & $\operatorname{truA}($ hisT)290::Tn5 & J. Roth, Utah \\
\hline GT 5880 & $\operatorname{tgt}:: \operatorname{Tn} 10 d \mathrm{Cm}$ & Urbonavičius et al. 2001 \\
\hline GT523 & $\operatorname{miaA} 1$ & Ericson and Bjök 1986 \\
\hline GT2176 & miaB2508::Tn 10dCm & Esberg and Björk 1995 \\
\hline GT3034 & miaE2507::MudP & Persson and Björk 1993 \\
\hline GT4946 & $\operatorname{mia} A 1, \operatorname{mia} B 2508:: \operatorname{Tn} 10 d \mathrm{Cm}$ & This work \\
\hline \multicolumn{3}{|l|}{ E. coli } \\
\hline TH98 & $\Delta($ pro-lac $), \arg E(\mathrm{am}),\left(\mathrm{val}^{\mathrm{R}}\right), i / v-135:: \operatorname{Tn} 10$, nalA, rif, mnmE+ & Urbonavičius et al. 2001 \\
\hline TH99 & $\Delta($ pro-lac $), \arg E(\mathrm{am}),\left(\mathrm{val}^{\mathrm{R}}\right)$, ilv-135::Tn 10, nalA, rif, mnmE & Urbonavičius et al. 2001 \\
\hline TH193 & ara, $\Delta$ (pro-lac), nalA, $\arg E(\mathrm{am})$, rif, thi, $m n m A$ & Urbonavičius et al. 2001 \\
\hline TH194 & ara, $\Delta$ (pro-lac), nalA, argE (am), rif, thi, $m n m A+$ & Urbonavičius et al. 2001 \\
\hline GBEC384 & $=\mathrm{CSH} 41 \Delta($ lac-pro), galE & CSH laboratories \\
\hline GRB1488 & $\Delta($ lac-pro $)$, galE, truA(hisT)::kan & This work \\
\hline GRB1490 & $\Delta$ (lac-pro), galE, truB2422::mini-Tn $10 \mathrm{Cm}$ & Urbonavičius et al. 2002 \\
\hline \multicolumn{3}{|l|}{ S. cerevisiae } \\
\hline GBY15 & Mat a, his3s1, leu $\Delta 0, \operatorname{met} 15 \Delta 0$, ura3 $\Delta 0, \operatorname{trm} 5:: \operatorname{kanM} X 4$ & Research Genetics \\
\hline GBY18 & Mat a, his3s1, leu $\Delta 0$, met15 $\Delta 0$, ura3 $\Delta 0$, TRM5 & Research Genetics \\
\hline
\end{tabular}


TABLE 2. Assay systems used to monitor various tRNA modifications in -1 frameshifting

\begin{tabular}{|c|c|c|c|c|c|c|c|}
\hline Site & Organism & $\begin{array}{c}\text { Mutants } \\
\text { used }\end{array}$ & $\begin{array}{l}\text { Heptameric } \\
\text { sequence }^{\mathrm{a}}\end{array}$ & tRNA in P-site & $\begin{array}{l}\text { Modification tested } \\
\text { in P-site tRNA }\end{array}$ & tRNA in A-site & $\begin{array}{l}\text { Modification tested } \\
\text { in A-site tRNA }\end{array}$ \\
\hline HIV & S. typh. & $\operatorname{mia} A$ & U-UUU-UUA & tRNA $_{\mathrm{GAA}}^{\mathrm{Phe}}$ & $\mathrm{ms}^{2} \mathrm{io}^{6}-$ of $\mathrm{ms}^{2}$ io $^{6} \mathrm{~A} 37$ & tRNA $\mathrm{cmnm}_{\mathrm{cm} \mathrm{UmAA}}^{\mathrm{Leu}}$ & $\mathrm{ms}^{2} \mathrm{io}^{6}-$ of $\mathrm{ms}^{2} \mathrm{io}^{6} \mathrm{~A} 37$ \\
\hline HIV & S. typh. & $\operatorname{mia} B$ & U-UUU-UUA & tRNA ${ }_{\mathrm{GAA}}^{\text {Phe }}$ & $\mathrm{ms}^{2}-$ of $\mathrm{ms}^{2} \mathrm{io}^{6} \mathrm{~A} 37$ & tRNA ${ }_{\mathrm{cmnm} 5 \mathrm{LumAA}}^{\mathrm{Leu}}$ & $\mathrm{ms}^{2}-$ of $\mathrm{ms}^{2} \mathrm{io}^{6} \mathrm{~A} 37$ \\
\hline HIV & S. typh. & $\operatorname{miaE}$ & U-UUU-UUA & tRNA & $o^{6}-$ of $\mathrm{ms}^{2} \mathrm{io}^{6} \mathrm{~A} 37$ & tRNA ${ }_{\mathrm{cmnm} 5 \mathrm{UmAA}}^{\mathrm{Leu}}$ & $o^{6}-$ of $\mathrm{ms}^{2} \mathrm{io}^{6} \mathrm{~A} 37$ \\
\hline HIV & S. typh. & $\operatorname{truA}$ & U-UUU-UUA & tRNA & $\Psi 39$ & tRNA & $\Psi 39$ \\
\hline HIV & E. coli & $\operatorname{tru} B$ & U-UUU-UUA & tRNA ${ }_{\mathrm{GAA}}^{\text {Phe }}$ & $\Psi 55$ & tRNA ${ }_{\mathrm{cmnm}}^{\mathrm{Leu}} 5 \mathrm{UmAA}$ & $\Psi 55$ \\
\hline $\operatorname{argl}$ & S. typh. & $\operatorname{mia} A, \operatorname{mia} B$ & G-UUU-UAU & tRNA ${ }_{G m A A}^{P h e}$ & $\mathrm{~ms}^{2} \mathrm{io}^{6}-$ of $\mathrm{ms}^{2} \mathrm{io}^{6} \mathrm{~A} 37$ & tRNA $A_{Q U A}^{T y r}$ & $\mathrm{~ms}^{2} \mathrm{io}^{6}-$ of $\mathrm{ms}^{2} \mathrm{io}^{6} \mathrm{~A} 37$ \\
\hline $\operatorname{argl}$ & S. typh. & $\operatorname{tg} t$ & G-UUU-UAU & tRNA ${ }_{\mathrm{GmAA}}^{\mathrm{Phe}}$ & None & tRNA $A_{Q U A}^{\text {Tyr }}$ & Q34 \\
\hline MMTV & E. coli & $m n m A$ & A-AAA-AAC & tRNA ${ }_{\text {mnmnss }}^{\text {Lys }} 2$ UuU & $\mathrm{s}^{2}-$ of $m \mathrm{~mm}^{5} \mathrm{~s}^{2} \mathrm{U} 34$ & tRNA $\mathrm{Asn}$ & None \\
\hline MMTV & E. coli & $m n m E$ & A-AAA-AAC & tRNA $A_{m n m n 5 s 2 U u U}^{\text {Lys }}$ & $m n m^{5}-$ of $m n m^{5} s^{2} U 34$ & tRNA $A_{Q U U}^{A s n}$ & None \\
\hline MMTV & S. typh. & $\operatorname{tg} t$ & A-AAA-AAC & tRNA ${ }_{\text {mnmn }}^{\text {Lys }}$ s $U \cup U$ & None & tRNA & Q34 \\
\hline MMTV & E. coli & $\operatorname{truA}$ & A-AAA-AAC & tRNA $A_{\text {mnmnss2 }}^{\text {Lys }}$ & $\Psi 39$ & tRNA $\mathrm{Aun}_{\mathrm{QuU}}^{\mathrm{ssn}}$ & $\Psi 39$ \\
\hline MMTV & E. coli & $\operatorname{tru} B$ & A-AAA-AAC & tRNA $\mathrm{m}_{\mathrm{mnmn} 5 \mathrm{~s} 2 \mathrm{LuU}}^{\mathrm{Lys}}$ & $\Psi 55$ & tRNA Asn & $\Psi 55$ \\
\hline HIV & S. cerev. & $\operatorname{trm} 5$ & U-UUU-UUA & tRNA ${ }_{\mathrm{GmAA}}^{\mathrm{Phe}}$ & Y-base & tRNA & $m^{1} \mathrm{G} 37$ \\
\hline $\mathrm{L}-\mathrm{A}$ & S. cerev. & $\operatorname{trm} 5$ & G-GGU-UUA & tRNA & None & tRNA & $\mathrm{m}^{1} \mathrm{G} 37$ \\
\hline
\end{tabular}

aThe first triplet denotes the codon in the P-site and the next triplet the codon in the A-site, if the frameshifting occurred as postulated by the "simultaneous slippage model."

shifting can be stimulated by $\mathrm{ms}^{2} \mathrm{io}^{6} \mathrm{~A} 37$ of, for example the $\mathrm{tRNA}_{\mathrm{GAA}}^{\mathrm{Phe}}$ reading the UUU codon at the P-site, provided that the ribosome makes a pause at the A-site (P-site effect by the undermodified tRNA). Because the modified nucleoside $\mathrm{ms}^{2} \mathrm{io}^{6} \mathrm{~A} 37$ is present in both of these tRNA, the effect monitored may be either caused by an A- or a P-site effect of the undermodified tRNA or a combined effect. Using the $\operatorname{argI}$ site (G-UUU-UAU) and the tgt mutant, which blocks formation of queuosine, we monitored specifically the influence of Q34 deficiency in $\mathrm{RNAA}_{\mathrm{QUA}}^{\mathrm{Tyr}}$ on reading the UAU codon in this sequence. Table 2 summarizes the assay systems used and indicates which modification was tested using the various mutants defective in tRNA modification. The assay systems, which are present on plasmids, were introduced into congenic strains of either E. coli, S. enterica, or S. cerevisiae, only differing in the allelic state of genes involved in the synthesis of various modified nucleosides. The frameshifting frequencies were compared with those in the wild type.

\section{Influence on $\mathbf{- 1}$ frameshifting by modification in position 34 (the wobble position)}

\section{Role of Q34}

The hypermodified base 7-((4.5-cis-dihydroxy-2-cyclopenten-1-yl)-amino) methyl)-7-deazaguanosine or queuosine $(\mathrm{Q})$ is present in position 34 in tRNAs specific for Tyr, His, Asn, and Asp, encoding UAU/C, CAU/C, AAU/C, and GAU/C, respectively. In a tgt mutant, these tRNAs have an unmodified G34 instead of Q34. Of the -1 frameshifting sites available, the presence of G34 instead of Q34 may influence the A-site selection of $\mathrm{TRNA}_{\mathrm{QUU}}^{\mathrm{Asn}}$ at the A-AAAAAC (pMMTV1284) or the A-site selection of tRNA $\mathrm{QUHA}_{\mathrm{Qu}}^{\mathrm{Ty}}$ at the G-UUU-UAU (pCF3). To test this hypothesis, we introduced either plasmid pMMTV1284 or plasmid pCFP3 into the wild type and the tgt mutant, respectively, and measured the level of frameshifting. No difference in -1 frameshifting was observed between wild type and the tgt mutant, suggesting that the A-site selection of $\mathrm{tRNA}_{\mathrm{QUU}}^{\mathrm{Asn}}$ or tRNA $\mathrm{QUA}_{\mathrm{QU}}^{\mathrm{Ty}}$ was not affected by Q34 (Fig. 2A).

\section{Role of $m n m^{5} s^{2} U 34$}

The modified nucleoside 5-methylaminomethyl-2-thio-uridine $\left(\mathrm{mnm}^{5} \mathrm{~s}^{2} \mathrm{U}\right)$ is present in position 34 in tRNAs specific for Gln, Lys, and Glu codons, which are part of the split codon boxes; that is, a codon box in which the four codons encode two amino acids. These tRNAs read codons CAA/G (Gln), AAA/G (Lys), and GAA/G (Glu). To test how the $\mathrm{mnm}^{5}$ - or the $\mathrm{s}^{2}$ - groups influence -1 frameshifting in the P-site by affecting the interaction of tRNA $\mathrm{mmnm}_{\mathrm{m} s 2 \mathrm{UuU}}^{\mathrm{Lys}}$ with the AAA codon, we introduced plasmid MMTV1284 (AAAA-AAC) into wild type and mnmE (containing $s^{2} \mathrm{U} 34$ instead of $\mathrm{mnm}^{5} \mathrm{~s}^{2} \mathrm{U} 34$ ) or $m n m A$ (containing $\mathrm{mnm}^{5} \mathrm{U} 34$ ) mutants, and measured the level of frameshifting. Lack of the $\mathrm{mnm}^{5}$-group, as in the $m n m E$ mutant, reduced the rate of -1 frameshifting 1.7-fold, whereas lack of the $\mathrm{s}^{2}$-group, as in the $m n m A$ mutant, did not affect the frequency of -1 frameshifting (Fig. 2B).

\section{Influence on -1 frameshifting by modification in position 37}

\section{Role of $\mathrm{ms}^{2}{ }^{2} \mathrm{o}^{6} 37$}

The modified nucleoside 2-(methylthio- $N^{6}$-isopentenyl) adenosine $\mathrm{ms}^{2} \mathrm{i}^{6} \mathrm{~A} 37$ is present in all E. coli tRNAs reading codons starting with $\mathrm{U}$ except $\mathrm{RNAA}_{\mathrm{GGA}}^{\mathrm{Ser} \mathrm{I}, \mathrm{V}}$ (Grosjean et al. 


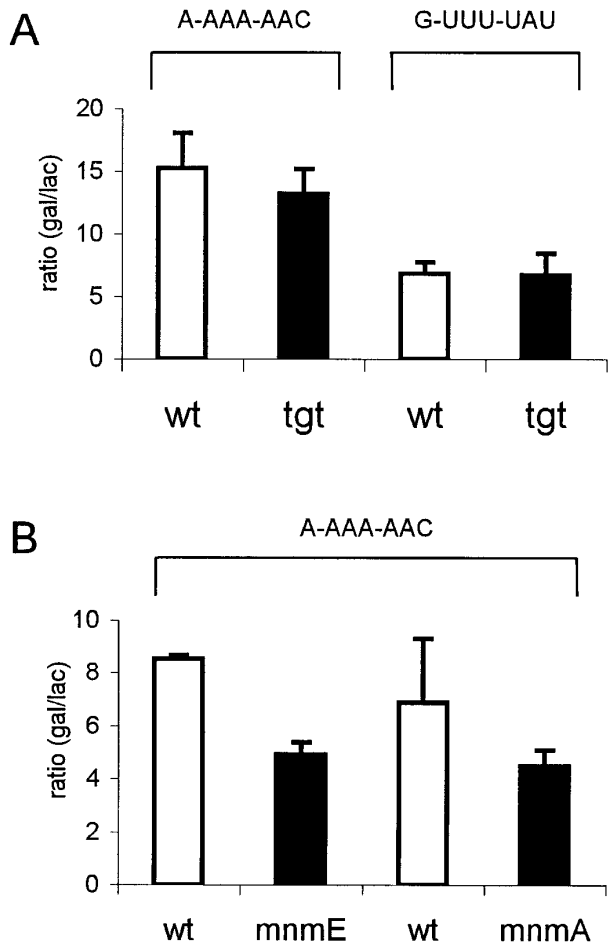

FIGURE 2. Influence of the Q34 and $m n m^{5} s^{2} \mathrm{U} 34$ on frameshifting at A-AAA-AAC and G-UUU-UAU sites. (A) In the tgt mutant, the

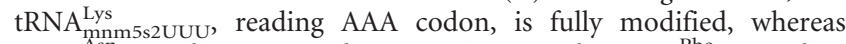
tRNA $\mathrm{QUU}_{\mathrm{QUU}}^{\mathrm{Asn}}$, reading AAC codon, contains $\mathrm{G} 34$; the tRNA $\mathrm{GmAA}_{\mathrm{GmA}}^{\mathrm{Phe}}$, reading UUU codon, is fully modified, whereas tRNA $\mathrm{OUA}_{\mathrm{OUA}}^{\mathrm{Ty}}$, reading UAU codon, contains G34. (B) In the mnmE mutant, AAA codon is read by

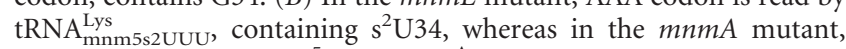
this tRNA contains $m n m^{5} \mathrm{U} 34$; $\mathrm{tRNA}_{\mathrm{QUU}}^{\mathrm{Asn}}$, reading AAC codon, is fully modified in both mutants. The frequency of frameshifting is expressed as the $\beta$-galactosidase activity normalized to the $\beta$-lactamase activity normalized encoded by the bla gene present on the same plasmid as that encoding lac $Z$ gene.

1985). In S. enterica, the hydroxylated derivative $\mathrm{ms}^{2} \mathrm{io}^{6} \mathrm{~A} 37$ is present in the corresponding tRNAs. Three S. enterica genes involved in the synthesis of $\mathrm{ms}^{2} \mathrm{io}^{6} \mathrm{~A} 37$ have been identified: miaA (Ericson and Björk 1986), miaB (Esberg and Björk 1995), and miaE (Persson and Björk 1993). The miaA mutant contains $\mathrm{A} 37$ instead of $\mathrm{ms}^{2} \mathrm{io}^{6} \mathrm{~A} 37$ in its tRNA, whereas the miaB mutant tRNA lacks the $\mathrm{ms}^{2}$-group and therefore contains mainly i $\mathrm{i}^{6} \mathrm{~A} 37$ and a small amount of io ${ }^{6} \mathrm{~A} 37$ (Esberg and Björk 1995). The miaE mutant lacks the hydroxyl-group and tRNA contains $\mathrm{ms}^{2} \mathrm{i}^{6} \mathrm{~A} 37$ instead of $\mathrm{ms}^{2}{ }^{2}{ }^{6} \mathrm{~A} 37$. We tested how the $\mathrm{ms}^{2} \mathrm{io}^{6}$ - (as in miaA), $\mathrm{ms}^{2}$ (as in miaB), and $0^{6}$ - (as in miaE) groups influence the -1

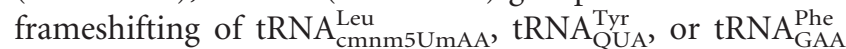
using the HIV (U-UUU-UUA) or the $\operatorname{argI}$ (G-UUU-UAU) frameshifting sites. We introduced the plasmids containing these sites into wild type and the miaA, miaB, and miaE mutants. We also introduced the plasmid containing the $\operatorname{argI}$ frameshifting site into wild type and the miaA-miaB double mutant, containing A37 instead of $\mathrm{ms}^{2}$ io ${ }^{6} \mathrm{~A} 37$. We measured the level of -1 frameshifting, and no difference between wild type and any of the mutants was observed (Fig. 3A).

\section{Role of $m^{1} G 37$ and $y W 37$}

The Trm5p protein is involved in the formation of modified nucleosides $\mathrm{m}^{1} \mathrm{G}$ and wybutosine ( $\mathrm{yW}$; nucleoside of the Y-base) at position 37 in a subset of tRNAs in yeast $S$. cerevisiae. The tricyclic nucleoside $\mathrm{yW}$ is present only in $\mathrm{tRNA}_{\mathrm{GmAA}}^{\mathrm{Phe}}$, and the first step in its synthesis is the formation of $m^{1} \mathrm{G} 37$ (Droogmans and Grosjean 1987). We have earlier shown that the trm 5 mutant is devoid of $\mathrm{yW}$ and has an unmodified G37 in its tRNA $\mathrm{GAA}_{\mathrm{GA}}^{\mathrm{Phe}}$ (Björk et al. 2001). The $\mathrm{m}^{1} \mathrm{G}$ in position 37 is present in several tRNA species, including tRNA $\mathrm{Aeu}_{\mathrm{U} ? \mathrm{AA}}^{\mathrm{Leu}}$. The trm 5 mutant of $S$. cerevisiae contains $\mathrm{G} 37$ in those tRNAs.
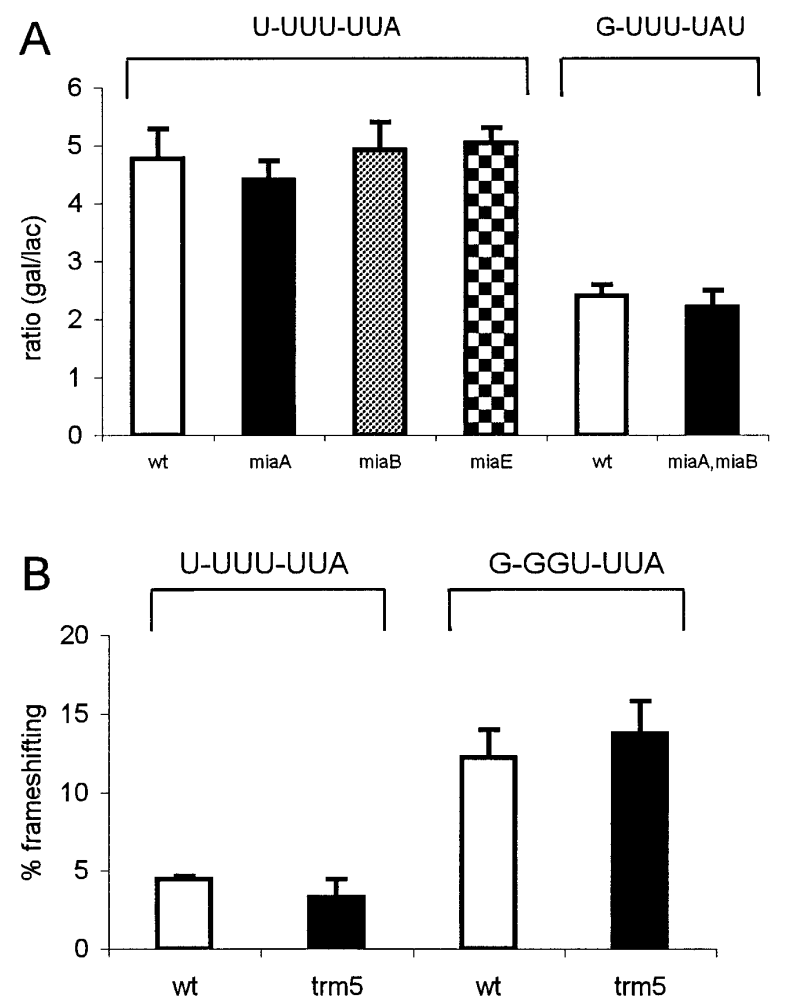

FIGURE 3. Influence of $\mathrm{ms}^{2} \mathrm{io}^{6} \mathrm{~A} 37$, yW37, and $\mathrm{m}^{1} \mathrm{G} 37$ on frameshifting at U-UUU-UUA, G-UUU-UAU, and G-GGU-UUA sites. (A) In the miaA mutant, both UUU and UUA codons at slippery sites are read by tRNAs containing $A 37$. In the miaB mutant, those tRNAs contain $10^{6} \mathrm{~A} 37$, and the miaE mutant, they contain $\mathrm{ms}^{2} \mathrm{i}^{6} \mathrm{~A} 37$. In the double miaA-miaB mutant, both UUU and UAU codons are read by tRNAs containing A37. The frequency of frameshifting is expressed as the $\beta$-galactosidase activity normalized to the $\beta$-lactamase activity normalized encoded by the bla gene present on the same plasmid as that encoding lac $Z$ gene. $(B)$ In the trm 5 mutant, $\mathrm{RNA}_{\mathrm{GmAA}}^{\mathrm{Phe}}$, reading the UUU codon, contains G37 instead of $y W 37$; tRNA $\mathrm{U}_{\mathrm{U} \text { ?AA }}^{\mathrm{Leu}}$, reading the UUA codon, contains G37 instead of $\mathrm{m}^{1} \mathrm{G} 37$, and tRNA $\mathrm{U}^{\mathrm{Gly}} \mathrm{CC}$, reading the GGU codon, contains $\mathrm{m}^{1} \mathrm{G} 37$. The frequency of frameshifting is expressed as the luciferase/ $\beta$-galactosidase ratio of a test construct (pAC1789 or pAC-LA) normalized to the ratio obtained with the in-frame control (pAC1790 or pAC-LAFF). 
To test how $\mathrm{m}^{1} \mathrm{G} 37$ influences reading frame maintenance by affecting A-site selection of tRNA $\mathrm{U}_{\mathrm{U} \text { ?AA }}^{\mathrm{Lu}}$, we introduced the L-A site (G-GGU-UUA) into wild type and the trm5 mutant, and measured the level of frameshifting. We found no difference in frameshifting (Fig. 3B). Thus, lack of $\mathrm{m}^{1} \mathrm{G} 37$ in $\mathrm{tRNA}_{\mathrm{U} \text { ?AA }}^{\mathrm{Leu}}$ had no influence on -1 frameshifting compared to the fully modified tRNA. The combined deficiency of $y W$ in $\mathrm{tRNA}_{\mathrm{GmAA}}^{\mathrm{Phe}}$ and of $\mathrm{m}^{1} \mathrm{G} 37$ in $\mathrm{tRNA} \mathrm{U}_{\mathrm{U} \text { ?A }}^{\mathrm{Leu}}$ had no impact on -1 frameshifting when monitored at the HIVsite (U-UUU-UUA) (Fig. 3B).

\section{Influence on $\mathbf{- 1}$ frameshifting by other modifications outside the anticodon}

Role of $\Psi 39$

The modified nucleoside pseudouridine $(\Psi)$ is present in the anticodon stem and loop of many bacterial tRNAs, including $t R N A_{c m n m 5 U m A A}^{\mathrm{Leu}}, \mathrm{tRNA}_{\mathrm{QUU}}^{\mathrm{Asn}}, \mathrm{RNA}_{\mathrm{GAA}}^{\mathrm{Phe}}$, and tRNA mys $_{\text {ms2UUU. The truA ( }}$ isT) gene product catalyzes the formation of $\Psi$ in position 39 in those tRNA species. To test how $\Psi 39$ influences reading frame maintenance by affecting A-site selection of $\mathrm{tRNA}_{\mathrm{cmnm} 5 \mathrm{UmAA}}^{\mathrm{Leu}}$ and/or P-site codon-anticodon interaction of the $\mathrm{tRNA}_{\mathrm{GAA}}^{\mathrm{Phe}}$, the HIV frameshifting site (U-UUU-UUA) was introduced into wild-type strain and the $\operatorname{truA}$ mutant, and the level of frameshifting was measured. We found no difference in -1 frameshifting between the wild type and the truA mutant (Fig. 4A). To test how $\Psi 39$ influences reading frame maintenance by affecting A-site selection of tRNA $\mathrm{QUU}_{\mathrm{QUU}}^{\mathrm{ssn}}$ and/or P-site codon-anticodon interaction of tRNA ${ }_{\text {mnm5s }}^{\text {Lys }}$ (UUU, the MMTV frameshifting site (A-AAA-AAC) was introduced into wild type and the truA mutant, and the level of frameshifting was measured. We observed no difference in -1 frameshifting between these strains, as in the case of pHIV-1 (Fig. 4A). Thus, $\Psi 39$ did not influence -1 frameshifting in any case.

\section{Role of $\Psi 55$}

The modified nucleoside $\Psi 55$ is part of the T $\Psi \mathrm{C}$ loop and thus is present in all tRNA species of E. coli and S. typhimurium. To test whether $\Psi 55$ influences frameshifting, either the HIV frameshifting site (U-UUU-UUA) or the MMTV frameshifting site (A-AAA-AAC) was introduced into wild type and the $t r u B$ mutant, and the level of frameshifting was measured. We found no influence of $\Psi 55$ on the frameshifting at both these frameshifting sites (Fig. 4B).

\section{DISCUSSION}

We have earlier shown that a common function for several tRNA modifications is to improve the reading frame maintenance by preventing +1 frameshift (Björk et al. 1989; Hagervall et al. 1993; Li et al. 1997; Urbonavičius et al.
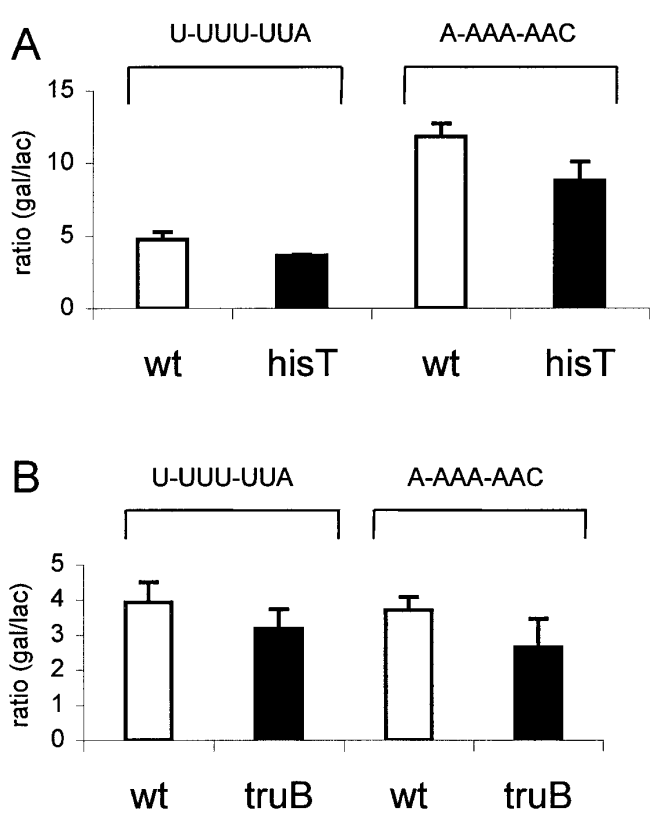

FIGURE 4. Influence of $\Psi 39$ and $\Psi 55$ on frameshifting at U-UUUUUA and A-AAA-AAC sites. (A) In the truA mutant, all tRNAs, reading codons at slippery sites, contain U39 instead of $\Psi 39$. (B) In the truB mutant, all tRNAs, reading codons at slippery sites, contain U55 instead of $\Psi 55$. The frequency of frameshifting is expressed as the $\beta$-galactosidase activity normalized to the $\beta$-lactamase activity normalized encoded by the bla gene present on the same plasmid as that encoding the lac $Z$ gene.

2001). Contrary to this observation, here we show that several different modified nucleosides do not influence or only slightly increase the frequency of -1 frameshifting (summarized in Table 3 ). Taken together, these observations suggest that the mechanism by which tRNA modification exerts its effect on the reading frame maintenance is different for shifts of the reading frame in the $5^{\prime}(-1)$ and the $3^{\prime}(+1)$ direction.

The Q34 deficiency in $\mathrm{tRNA}_{\mathrm{QUU}}^{\mathrm{Asn}}$ acting at the slippery sequence A-AAA-AAC did not influence the -1 frameshifting (Fig. 2A), as was observed for +1 frameshifting (Urbonavičius et al. 2001). Similarly, the absence of Q34 in tRNAAsn did not influence the level of -1 frameshifting at UUUA-AAC/U sites in the cos-cells and in vitro using the rabbit reticulocyte lysate (RRL) system (Marczinke et al. 2000). Using the same in vitro system, the level of -1 frameshifting at the A-AAA-AAC site only increased 1.5-fold when the Q-deficient $\mathrm{tRNA}$ Asn from yeast was added to the lysate (Carlson et al. 2001). When the effect by Q34 was analyzed in vivo using a Q34 deficient mutant of E. coli, frameshifting by tRNA $\mathrm{Leu}_{\mathrm{U} \text { ?AA }}^{\mathrm{Leu}}$ decreased 2-fold at the U-UUAAAC site (i.e., when $t R N A_{U \text { ?AA }}^{\mathrm{Leu}}$ interacted with the AAC codon) and increased 2-fold at the U-UUA-AAU site (i.e., when $\mathrm{RNA}_{\mathrm{U} \text { ?AA }}^{\mathrm{Leu}}$ interacted with the AAU codon; Brierley et al. 1997). The difference between those and our (Fig. 2A) results may be explained by presence of different tRNAs $\left(\mathrm{tRNA}_{\mathrm{cmnm} 5 \mathrm{UmAA}}^{\mathrm{Leu}}\right.$ versus tRNA ${ }_{\mathrm{mnm} 5 \mathrm{~s} 2 \mathrm{UUU}}^{\mathrm{Lys}}$ or $\mathrm{tRNA}_{\mathrm{GAA}}^{\mathrm{Phe}}$ ) in 
TABLE 3. Comparison of the effect of tRNA modification on -1 and +1 frameshifting

\begin{tabular}{|c|c|c|c|c|c|}
\hline \multirow[b]{2}{*}{ Modification tested } & \multirow{2}{*}{$\begin{array}{l}\text { Codon } \\
\text { tested }\end{array}$} & \multicolumn{2}{|c|}{ Increased -1 fs } & \multicolumn{2}{|c|}{ Increased +1 fs } \\
\hline & & P-site & A-site & P-site & A-site \\
\hline Q34 & UAU & ND & No & No & $Y_{e s}{ }^{a}$ \\
\hline Q34 & $\mathrm{AAC}$ & ND & No & ND & ND \\
\hline $\mathrm{s}^{2}-$ of $m n m^{5} \mathrm{~s}^{2} \mathrm{U} 34$ & AAA & No & ND & $Y_{e s}{ }^{a}$ & $Y_{e s}{ }^{a}$ \\
\hline$m n m^{5}-$ of $m n m^{5} s^{2} U 34$ & AAA & $\mathrm{No}^{\mathrm{b}}$ & ND & $Y_{e s}{ }^{a}$ & $Y_{e s}{ }^{a}$ \\
\hline $\mathrm{ms}^{2} \mathrm{io}^{6}$ - of $\mathrm{ms}^{2} \mathrm{io}^{6} \mathrm{~A} 37$ & UUU & No & ND & Yes $^{\mathrm{a}}$ & $\mathrm{No}^{\mathrm{c}}$ \\
\hline $\mathrm{ms}^{2}-$ of $\mathrm{ms}^{2} \mathrm{io}^{6} \mathrm{~A} 37$ & UUU & No & ND & $\mathrm{Yes}^{\mathrm{a}}$ & $\mathrm{No}^{\mathrm{c}}$ \\
\hline $\mathrm{o}^{6}-\mathrm{of}^{\mathrm{ms}} \mathrm{s}^{2} \mathrm{io}^{6} \mathrm{~A} 37$ & UUU & No & ND & $Y_{e s}{ }^{a}$ & ND \\
\hline $\mathrm{ms}^{2} \mathrm{io}^{6}-$ of $\mathrm{ms}^{2} \mathrm{io}^{6} \mathrm{~A} 37$ & UUA & ND & No & ND & ND \\
\hline $\mathrm{ms}^{2}-$ of $\mathrm{ms}^{2} \mathrm{io}^{6} \mathrm{~A} 37$ & UUA & ND & No & ND & ND \\
\hline $\mathrm{o}^{6}-$ of $\mathrm{ms}^{2} \mathrm{io}^{6} \mathrm{~A} 37$ & UUA & ND & No & ND & ND \\
\hline $\mathrm{ms}^{2} \mathrm{io}^{6}-$ of $\mathrm{ms}^{2} \mathrm{io}^{6} \mathrm{~A} 37$ & UAU & ND & No & $Y s^{\mathrm{a}}$ & $Y^{c} s^{c}$ \\
\hline Y-base & UUU & No & ND & ND & ND \\
\hline$m^{1} G 37$ & UUA & ND & No & ND & ND \\
\hline$\Psi 39$ & UUU & No & ND & $\mathrm{No}^{\mathrm{d}}$ & ND \\
\hline$\Psi 39$ & UUA & ND & No & ND & ND \\
\hline$\Psi 39$ & AAA & No & ND & ND & ND \\
\hline$\Psi 39$ & AAC & ND & No & ND & ND \\
\hline$\Psi 55$ & UUU & No & ND & $\mathrm{No}^{\mathrm{e}}$ & ND \\
\hline$\Psi 55$ & UUA & ND & No & ND & ND \\
\hline$\Psi 55$ & AAA & No & ND & ND & $\mathrm{No}^{\mathrm{e}}$ \\
\hline$\Psi 55$ & AAC & ND & No & ND & ND \\
\hline
\end{tabular}

(ND) Not determined.

adapted from Urbonavičius et al. (2001).

${ }^{b}$ Reduced level of frameshifting was observed.

cAdapted from Li et al. (1997).

${ }^{\mathrm{d}}$ Adapted from Qian (1997).

eAdapted from Urbonavičius et al. (2002).

the P-site. Apparently, Q34 in $\mathrm{tRNA}_{\mathrm{QUU}}^{\mathrm{Asn}}$ interacting with the AAC codon slightly stimulates -1 frameshift errors, whereas when interacting with the AAU codon, it slightly prevents -1 frameshifts. Therefore, presence of Q34 in the tRNA stimulates -1 frameshifting when it interacts with C, whereas it prevents the same error if interacting with $U$ as the third nucleoside of the codon. Similarly, when monitoring +1 frameshifting, Q34 prevented such errors when interacting with a U-ending codon (Urbonavičius et al. 2001). Q34 deficiency of tRNA ${ }^{\text {His }}$ does not influence -1 frameshifting on the sequence U UUC AUA in vivo in $E$. coli (Masucci et al. 2002), consistent with our observation and that of Brierly et al. (1997) that Q34 does not influence -1 frameshifting. Because in most cases no effect on -1 frameshift that could be attributed to $Q$ was observed and if an effect was observed, it was small, these results show that Q34 has no major role in preventing -1 frameshifting.

Lack of either the $\mathrm{mnm}^{5}$ - or the $\mathrm{s}^{2}$-group of $\mathrm{mnm}^{5} \mathrm{~s}^{2} \mathrm{U} 34$ increases the frequency of +1 frameshifting for the

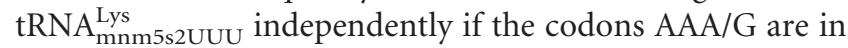
the A- or in the P-site (Urbonavičius et al. 2001). In contrast, frequency of -1 frameshifting decreased at the A-

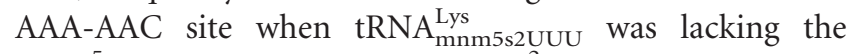
$\mathrm{mnm}^{5}$-group, whereas lack of the $\mathrm{s}^{2}$-group did not make any difference (Fig. 2B). Similarly, in E. coli, the $\mathrm{s}^{2}$ - or the $m m^{5}$-group each has very little or no influence on -1 frameshifting at a U-UUA-AAG site, and the $s^{2}$-group has no influence on -1 frameshifting at the U-UUA-AAA site (Brierley et al. 1997). However, lack of the $\mathrm{mnm}^{5}$-group increases the -1 frameshifting at the slippery U-UUA-AAA sites twofold (Brierley et al. 1997). Thus, contrary to the large impact of $m n m^{5} s^{2} \mathrm{U} 34$ to prevent +1 shifts, its role in -1 frameshifting is minor, and, in fact, in some cases the presence of it increases the -1 frameshift error.

Transfer RNA from all organisms frequently contains modified nucleosides at position 37 ( $3^{\prime}$ and adjacent to the anticodon). Two such modified nucleosides are $\mathrm{ms}^{2} \mathrm{io}^{6} \mathrm{~A} 37$ and $\mathrm{m}^{1} \mathrm{G} 37$, which both prevent +1 frameshift errors (Björk et al. 1989; Hagervall et al. 1993; Li et al. 1997; Urbonavičius et al. 2001). However, $\mathrm{ms}^{2} \mathrm{io}^{6} \mathrm{~A} 37$ did not influence -1 frameshifting (Fig. 3A) at any sequence tested. We found also no effect of $\mathrm{m}^{1} \mathrm{G} 37$ in yeast tRNA $\mathrm{U}_{\mathrm{U} \text { ?AA }}^{\mathrm{Leu}}$ on -1 frameshifts (Fig. 3B). Thus, whereas $\mathrm{m}^{1} \mathrm{G} 37$ and $\mathrm{ms}^{2} \mathrm{io}^{6} \mathrm{~A} 37$ are very important in preventing +1 frameshifts, they apparently have no role in preventing -1 frameshifts.

The highly complex tricyclic modified nucleoside wybutosine $(\mathrm{yW})$ is present at position 37 only in eukaryotic tRNA $\mathrm{GmAA}_{\mathrm{Gm}}^{\mathrm{Ph}}$. Using the rabbit reticulocyte lysate (RRL) in vitro translation system, a threefold increase in -1 frameshifting at the A-AAU-UUU site was attributed to the exchange of $y W 37$ to $\mathrm{m}^{1} \mathrm{G} 37$ in $\mathrm{tRNA}_{\mathrm{GmAA}}^{\mathrm{Phe}}$, reading UUU in the A-site (Carlson et al. 1999, 2001). However, the level of -1 frameshifting at U-UUU-UUU/C sites, which have codons read by $\mathrm{RNA}_{\mathrm{GmAA}}^{\mathrm{Phe}}$ both in P- and A-sites, was the

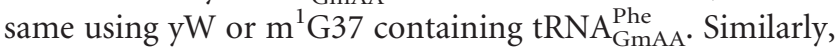
we observed in vivo no influence by yW37 on -1 frameshifting at the U-UUU-UUA site (Fig. 3B), which has UUU in the P-site, similarly to the U-UUU-UUU/C sequence. Thus, lack of yW37 of tRNA $\mathrm{Gme}$ PhA decoding UUU in the $\mathrm{P}$-site did not influence -1 frameshifting either in vivo or in vitro. Because lack of $y \mathrm{~W} 37$ of $\mathrm{tRNA}_{\mathrm{GmAA}}^{\mathrm{Phe}}$ increased -1 frameshifting at A-AAU-UUU but not at U-UUU-UUU/C (Carlson et al. 1999, 2001), the yW37-mediated effect on tRNA ${ }_{\text {GmAA }}^{\text {Phe }}$ decoding UUU in the A-site may be sensitive to which tRNA is occupying the P-site (peptidyl-tRNA ${ }^{\text {Lys }}$ versus peptidyl-tRNA ${ }^{\text {Phe }}$ ).

Taken together, whereas modifications such as $\mathrm{ms}^{2} \mathrm{io}^{6} \mathrm{~A} 37$ and $\mathrm{m}^{\mathrm{l}} \mathrm{G} 37$ at position 37 have a profound influence on preventing +1 frameshifting, these modifications and yW37 have no or only a minor effect on -1 frameshift errors.

According to our model (Fig. 1; Urbonavičius et al. 2001; Stahl et al. 2002), +1 frameshifts occur after translocation and by slippage of the P-site tRNA when the A-site is empty. According to the simultaneous slippage model (Jacks et al. 1988), -1 frameshifts occur after the A-site is filled, by simultaneous slippage of the tRNAs present in both A- and $\mathrm{P}$-sites, that is prior to translocation. In general, our results (Table 3) and those of others (Hagervall et al. 1993; Brierley et al. 1997; Carlson et al. 1999; Marczinke et al. 2000) sug- 
gest that tRNA modifications have no or only a minor effect on -1 frameshifts. In fact, in some cases, the presence of the modified nucleoside actually stimulates -1 frameshifting (Fig. 2B) in sharp contrast to earlier observations that the presence of several modifications in tRNA prevents +1 frameshifts (Urbonavičius et al. 2001). These results suggest that -1 and +1 frameshifting occur by distinct mechanisms. It is known that +1 frameshifting is quite sensitive to the rate of recognition of the codon in the empty A-site, for example, because of slow selection of mutant tRNAs (Li et al. 1997; Qian and Björk 1997; Urbonavičius et al. 2001) or low concentration of cognate tRNA (Belcourt and Farabaugh 1990; Farabaugh et al. 1993). Such slow A-site decoding increases the probability of a forward shift of the reading frame. In contrast, a -1 slippage by the peptidyltRNA would depend on a movement of the apparently strongly bound deacylated tRNA in the E-site (for a review, see Ramakrishnan 2002), suggesting that such a peptidyltRNA slippage is unlikely. According to the simultaneous slippage model, the E-site is empty at the time of slippage. Still, both tRNAs interact with various parts of the ribosome, making the presence of modified nucleoside of minor importance to inhibit a simultaneous slippage in the $5^{\prime}$ direction. Perhaps interactions between the two tRNAs, the mRNA, and the ribosome during -1 simultaneous slippage frameshifting are epistatic to small structural changes in the tRNA, such as those induced by hypomodification. Such considerations could explain our inability to show an effect of hypomodification on -1 frameshifting and why tRNA modification is more important to prevent +1 than -1 frameshift errors. Our results are therefore consistent with the predictions of the simultaneous slippage model (Jacks et al. 1988).

\section{MATERIALS AND METHODS}

\section{Plasmids, strains, and growth conditions}

Plasmids and strains, which were constructed by standard genetic methods (Davis et al. 1980), are listed in Table 1. S. enterica serovar Typhimurium strains harboring various plasmids were grown at $37^{\circ} \mathrm{C}$ in the rich medium $\mathrm{NB}+\mathrm{AV}+\mathrm{ADE}$, Difco nutrient broth $(0.8 \%$; Difco Laboratories) supplemented with the aromatic amino acids $(\mathrm{A})$, aromatic vitamins $(\mathrm{V})$, and adenine (ADE; Davis et al. 1980). Strains of E. coli were grown at $37^{\circ} \mathrm{C}$ in $\mathrm{LB}$ medium (Bertani 1951). Strains of $S$. cerevisiae were grown at $30^{\circ} \mathrm{C}$ in SD medium supplemented with appropriate amino acids or uracil (Adams et al. 1997).

\section{Determination of the $\beta$-galactosidase, $\beta$-lactamase, and luciferase activity}

In bacteria, $\beta$-galactosidase and $\beta$-lactamase activity and the frequency of frameshifting were measured as described earlier (Hagervall et al. 1993; Li et al. 1997). In yeast, $\beta$-galactosidase and luciferase activities and the frequency of frameshifting were mea- sured as described previously (Stahl et al. 1995). Statistical variation was calculated using the $t$ test with two tails. A difference in the frequency of frameshifting was considered significant when $p<0.05$.

\section{ACKNOWLEDGMENTS}

This work was supported by grants to G.R.B. from the Swedish Cancer Foundation (project 680) and Science Research Council (project B-BU 2930) and to P.J.F. from the U.S. National Institute of General Medical Sciences (GM-29480). We thank D. Ågren and A. Raman for assistance in some experiments, and T. Hagervall for critical reading of the manuscript.

The publication costs of this article were defrayed in part by payment of page charges. This article must therefore be hereby marked "advertisement" in accordance with 18 USC section 1734 solely to indicate this fact.

Received February 4, 2003; accepted March 17, 2003.

\section{REFERENCES}

Adams, A., Gottschling, D.E., Kaiser, C.A., and Stearns, T. 1997. Methods in yeast genetics. Cold Spring Harbor Laboratory Press, Cold Spring Harbor, New York.

Barak, Z., Lindsley, D., and Gallant, J. 1996. On the mechanism of leftward frameshifting at several hungry codons. J. Mol. Biol. 256: 676-684.

Belcourt, M.F. and Farabaugh, P.J. 1990. Ribosomal frameshifting in the yeast retrotransposon Ty: tRNAs induce slippage on a 7 nucleotide minimal site. Cell 62: 339-352.

Bertani, G. 1951. Studies on lysogenesis. J. Bacteriol. 62: 293-300.

Bidou, L., Stahl, G., Hatin, I., Namy, O., Rousset, J.P., and Farabaugh, P.J. 2000. Nonsense-mediated decay mutants do not affect programmed -1 frameshifting. RNA 6: 952-961.

Björk, G.R., Wikström, P.M., and Byström, A.S. 1989. Prevention of translational frameshifting by the modified nucleoside 1-methylguanosine. Science 244: 986-989.

Björk, G.R., Jacobsson, K., Nilsson, K., Johansson, M.J., Byström, A.S., and Persson, O.P. 2001. A primordial tRNA modification required for the evolution of life? EMBO J. 20: 231-239.

Brierley, I., Meredith, M.R., Bloys, A.J., and Hagervall, T.G. 1997. Expression of a coronavirus ribosomal frameshift signal in Escherichia coli: Influence of tRNA anticodon modification on frameshifting. J. Mol. Biol. 270: 360-373.

Carlson, B.A., Kwon, S.Y., Chamorro, M., Oroszlan, S., Hatfield, D.L., and Lee, B.J. 1999. Transfer RNA modification status influences retroviral ribosomal frameshifting. Virology 255: 2-8.

Carlson, B.A., Mushinski, J.F., Henderson, D.W., Kwon, S.Y., Crain, P.F., Lee, B.J., and Hatfield, D.L. 2001. 1-Methylguanosine in place of $\mathrm{Y}$ base at position 37 in phenylalanine tRNA is responsible for its shiftiness in retroviral ribosomal frameshifting. Virology 279: 130-135.

Davis, W., Botstein, D., and Roth, J.R. 1980. A manual for genetic engineering: Advanced bacterial genetics. Cold Spring Harbor Laboratory, Cold Spring Harbor, New York.

Dinman, J.D., Icho, T., and Wickner, R.B. 1991. A -1 ribosomal frameshift in a double-stranded RNA virus of yeast forms a gag-pol fusion protein. Proc. Natl. Acad. Sci. 88: 174-178.

Droogmans, L. and Grosjean, H. 1987. Enzymatic conversion of guanosine $3^{\prime}$ adjacent to the anticodon of yeast tRNA ${ }^{\text {Phe }}$ to $N^{1}$-methylguanosine and the wye nucleoside: Dependence on the anticodon sequence. EMBO J. 6: 477-483.

Ericson, J.U. and Björk, G.R. 1986. Pleiotropic effects induced by modification deficiency next to the anticodon of tRNA from Sal- 


\section{Urbonavičius et al.}

monella typhimurium LT2. J. Bacteriol. 166: 1013-1021.

Esberg, B. and Björk, G.R. 1995. The methylthio group $\left(\mathrm{ms}^{2}\right)$ of $N^{6}-$ (4-hydroxyisopentenyl)-2-methylthioadenosine $\left(\mathrm{ms}^{2} \mathrm{io}^{6} \mathrm{~A}\right)$ present next to the anticodon contributes to the decoding efficiency of the tRNA. J. Bacteriol. 177: 1967-1975.

Farabaugh, P.J. 2000. Translational frameshifting: Implications for the mechanism of translational frame maintenance. Prog. Nucleic Acid Res. Mol. Biol. 64: 131-170.

Farabaugh, P.J., Zhao, H., and Vimaladithan, A. 1993. A novel programed frameshift expresses the POL3 gene of retrotransposon Ty3 of yeast: Frameshifting without tRNA slippage. Cell 74: 93-103.

$\mathrm{Fu}, \mathrm{C}$. and Parker, J. 1994. A ribosomal frameshifting error during translation of the argI mRNA of Escherichia coli. Mol. Gen. Genet. 243: 434-441.

Grosjean, H., Nicoghosian, K., Haumont, E., Soll, D., and Cedergren, R. 1985. Nucleotide sequences of two serine tRNAs with a GGA anticodon: The structure-function relationships in the serine family of E. coli tRNAs. Nucleic Acids Res. 13: 5697-5706.

Hagervall, T.G., Tuohy, T.M., Atkins, J.F., and Björk, G.R. 1993. Deficiency of 1-methylguanosine in tRNA from Salmonella typhimurium induces frameshifting by quadruplet translocation. J. Mol. Biol. 232: 756-765.

Horsfield, J.A., Wilson, D.N., Mannering, S.A., Adamski, F.M., and Tate, W.P. 1995. Prokaryotic ribosomes recode the HIV-1 gagpol-1 frameshift sequence by an E/P site post-translocation simultaneous slippage mechanism. Nucleic Acids Res. 23: 1487-1494.

Jacks, T., Madhani, H.D., Masiarz, F.R., and Varmus, H.E. 1988. Signals for ribosomal frameshifting in the Rous sarcoma virus gag-pol region. Cell 55: 447-458.

Kurland, C.G., Hughes, D., and Ehrenberg, M. 1996. Limitations of translational accuracy. In Escherichia coli and Salmonella: Cellular and molecular biology (eds. F.C. Neidhardt et al.), pp. 979-1004. ASM Press, Washington, DC.

Li, J., Esberg, B., Curran, J.F., and Björk, G.R. 1997. Three modified nucleosides present in the anticodon stem and loop influence the in vivo aa-tRNA selection in a tRNA-dependent manner. J. Mol. Biol. 271: 209-221.

Marczinke, B., Hagervall, T., and Brierley, I. 2000. The Q-base of asparaginyl-tRNA is dispensable for efficient -1 ribosomal frameshifting in eukaryotes. J. Mol. Biol. 295: 179-191.

Masucci, J.P., Gallant, J., Lindsley, D., and Atkinson, J. 2002. Influence of the relA gene on ribosomal frameshifting. Mol. Genet. Genomics 268: $81-86$.

Persson, B.C. and Björk, G.R. 1993. Isolation of the gene (miaE) encoding the hydroxylase involved in the synthesis of 2-methylthio-cis-ribozeatin in tRNA of Salmonella typhimurium and characterization of mutants. J. Bacteriol. 175: 7776-7785.

Qian, Q. 1997. Transfer RNA modification and translational frameshifting. Solfjädern Offset AB, Umeå, Sweden.

Qian, Q. and Björk, G.R. 1997. Structural alterations far from the anticodon of the tRNA ${ }^{\text {ProGGG }}$ of Salmonella typhimurium induce +1 frameshifting at the peptidyl-site. J. Mol. Biol. 273: 978-992.

Ramakrishnan, V. 2002. Ribosome structure and the mechanism of translation. Cell 108: $557-572$.

Rozenski, J., Crain, P.F., and McCloskey, J.A. 1999. The RNA Modification Database: 1999 update. Nucleic Acids Res. 27: 196-197.

Stahl, G., Bidou, L., Rousset, J.P., and Cassan, M. 1995. Versatile vectors to study recoding: Conservation of rules between yeast and mammalian cells. Nucleic Acids Res. 23: 1557-1560.

Stahl, G., McCarty, G.P., and Farabaugh, P.J. 2002. Ribosome structure: Revisiting the connection between translational accuracy and unconventional decoding. Trends Biochem. Sci. 27: 178-183.

Urbonavičius, J., Qiang, Q., Durand, J.M.B., Hagervall, T.G., and Björk, G.R. 2001. Improvement of reading frame maintenance is a common function for several tRNA modifications. EMBO J. 20: $4863-4873$.

Urbonavičius, J., Durand, J., and Björk, G.R. 2002. Three modifications in the D and T arms of tRNA influence translation in Escherichia coli and expression of virulence genes in Shigella flexneri. J. Bacteriol. 184: 5348-5357.

Weiss, R., and Gallant, J. 1983. Mechanism of ribosome frameshifting during translation of the genetic code. Nature 302: 389-393.

Weiss, R.B., and Gallant, J.A. 1986. Frameshift suppression in aminoacyl-tRNA limited cells. Genetics 112: 727-739.

Weiss, R., Dunn, D.M., Atkins, J.F., and Gesteland, R.F. 1987. Slippery runs, shifty stops, backward steps, and forward hops: $-2,-1,+1$, $+2,+5$, and +6 ribosomal frameshfifting. Cold Spring Harbor Symp. Quant. Biol. 52: 687-693.

Weiss, R.B., Dunn, D.M., Shuh, M., Atkins, J.F., and Gesteland, R.F. 1989. E. coli ribosomes re-phase on retroviral frameshift signals at rates ranging from 2 to 50 percent. New Biol. 1: 159-169.

Weiss, R.B., Dunn, D.M., Atkins, J.F., and Gesteland, R.F. 1990. Ribosomal frameshifting from -2 to +5 nucleotides. Progr. Nucl. Acid Res. Mol. Biol. 39: 159-183.

Yelverton, E., Lindsley, D., Yamauchi, P., and Gallant, J.A. 1994. The function of a ribosomal frameshifting signal from human immunodeficiency virus-1 in Escherichia coli. Mol. Microbiol. 11:303313. 

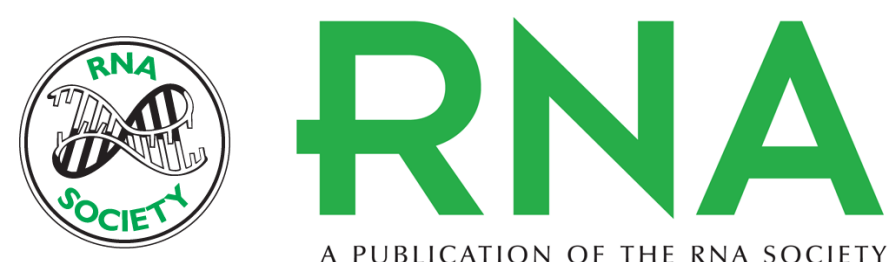

A PUBLICATION OF THE RNA SOCIETY

\section{Transfer RNA modifications that alter +1 frameshifting in general fail to affect -1 frameshifting}

JAUNIUS URBONAVIC?IUS, GUILLAUME STAHL, JÉRÔME M.B. DURAND, et al.

RNA 2003 9: 760-768

References This article cites 37 articles, 12 of which can be accessed free at: http://rnajournal.cshlp.org/content/9/6/760.full.html\#ref-list-1

\section{License}

Email Alerting Receive free email alerts when new articles cite this article - sign up in the box at the Service top right corner of the article or click here. 